\title{
Misoprostol does not alter the pharmacokinetics of propranolol
}

\author{
P.N. Bennett ${ }^{1}$, G.C. Fenn² ${ }^{2}$ L.J. Notarianni' ${ }^{1}$ and C.E. Lee $^{2}$
}

${ }^{1}$ Clinical Pharmacology Unit, Royal United Hospital, Combe Park, Bath BA1 3NG and School of

Pharmacy and Pharmacology, University of Bath, Claverton Down, Bath BA2 $7 A$ Y and ${ }^{2}$ G.D. Searle \& Co Ltd, High Wycombe, Bucks HP12 4HL, UK

\begin{abstract}
Summary: Twelve healthy volunteers took part in a randomised, double-blind, balanced, cross-over study to investigate the effect of misoprostol on the pharmacokinetics of propranolol. The subjects took propranolol $80 \mathrm{mg}$ twice daily by mouth plus either misoprostol $400 \mu \mathrm{g}$ twice daily or placebo by mouth for 14.5 days, followed by a 2-week washout period, followed by the alternate treatment for 14.5 days. Misoprostol had no significant effect on the $t / 2, C_{\max }$ or $A U C$ of propranolol either after a single dose or at steady state.
\end{abstract}

\section{Introduction}

Misoprostol is a synthetic prostaglandin $E_{1}$ analogue which is widely used for the treatment of peptic ulcer and for the prophylaxis and treatment of ulcer caused by non-steroidal anti-inflammatory drugs. ${ }^{1}$ In an earlier study ${ }^{2}$ we reported that plasma concentrations of propranolol rose both during and after cessation of concurrent misoprostol administration. These findings were unexpected and difficult to explain. An effect on hepatic enzyme activity was incompatible with our observed lack of effect of misoprostol on antipyrine clearance, and an alternative explanation was that steady state plasma concentration of propranolol had not been reached in the design used in the original study. We have repeated the study with a design that ensures the attainment of steady state conditions of dosing.

\section{Materials and methods}

The study was approved by the Bath DHA Research Ethics Committee. Twelve volunteers, 8 males, $22-29$ years, $51.8-96.9 \mathrm{~kg}$ were studied. Each was found to be healthy by physical examination, haematological and biochemical profiles, each was a non-smoker and an extensive metaboliser of debrisoquine. ${ }^{3}$ Each volunteer maintained a daily record of his or her intake of alcohol and caffeine-containing drinks; males limited

Correspondence: P.N. Bennett, M.D., F.R.C.P., School of Pharmacy and Pharmacology, University of Bath, Claverton Down, Bath BA2 7AY, UK

Accepted: 29 October 1990 alcohol consumption to 20 units and females to 13 units per week.

A randomized, double-blind, balanced, crossover design was used. Each volunteer received in one part of the study propranolol $80 \mathrm{mg}$ twice daily by mouth plus misoprostol $400 \mu \mathrm{g}$ twice daily by mouth for 14.5 days and in the other part of the study propranolol $80 \mathrm{mg}$ twice daily by mouth plus placebo misoprostol twice daily by mouth for 14.5 days, with a 14-day washout period between the two parts of the study. In each part of the study, blood was taken for assay of plasma propranolol on the first day of receipt of propranolol (after a single dose) and on the 15th day of receipt (at steady state) at $0,1,2,3,4,6,8,10$ and $12 \mathrm{~h}$ after dosing. Propranolol was assayed by high performance liquid chromatography. ${ }^{4}$ Coefficients of variation of standard samples were $(n=10) 7 \%$ at $20 \mu \mathrm{g} / 1$ and $5 \%$ at $200 \mu \mathrm{g} / 1$.

Plasma half-lives $(t / 2)$ were calculated by least squares linear regression analysis of the logarithm of concentration during the terminal phase, on time. Areas under the plasma concentration-time curves (AUC) to $12 \mathrm{~h}$ were calculated by the trapezoidal rule. ${ }^{5}$ AUC and $C_{\max }$ values were logarithmically transformed and submitted to analysis of variance with sequence, subjects within sequence, period and treatment as factors in the model. For $t / 2$, differences between treatments were tested using the Wilcoxon signed-rank test.

\section{Results}

Table I gives mean values for $\mathrm{t} / 2, \mathrm{C}_{\max }$ and AUC. After a single dose of propranolol the ratio of 
Table I Effect of misoprostol on propranolol pharmacokinetics in healthy volunteers

\begin{tabular}{llll}
\hline & $\begin{array}{c}t / 2^{*} \\
(h)\end{array}$ & $\begin{array}{c}\text { Propranolol } \\
C_{\text {max }}^{*} \\
(\mu g / l)\end{array}$ & $\begin{array}{c}A U C^{*} \\
(\mu \mathrm{g} / \mathrm{l} \mathrm{h})\end{array}$ \\
\hline $\begin{array}{l}\text { 1. After single dose } \\
\text { (propranolol } 80 \mathrm{mg} \\
\text { by mouth) }\end{array}$ & & & \\
$\begin{array}{l}\text { a) with placebo } \\
\text { b) with misoprostol } \\
400 \mu g \text { once daily } \\
\text { by mouth }\end{array}$ & $3.1 \pm 1.0$ & $77.3 \pm 39.6$ & $422.4 \pm 174.4$ \\
$\begin{array}{l}\text { 2. At steady state } \\
\text { (propranolol 80 mg } \\
\text { twice daily for 14.5 days) }\end{array}$ & & $65.4 \pm 25.0$ & $342.6 \pm 153.3$ \\
$\begin{array}{l}\text { a) with placebo } \\
\text { b) with misoprostol } \\
400 \mu g \text { twice daily } \\
\text { by mouth for } 14.5 \text { days }\end{array}$ & $3.6 \pm 1.0$ & $118.0 \pm 91.5$ & $621.6 \pm 362.6$ \\
\hline
\end{tabular}

*All values are means \pm s.d.; $P>0.05$.

misoprostol:placebo for AUC was 0.81 with the $95 \%$ confidence interval (CI) $0.60-1.10$ and for $\mathrm{C}_{\max }$ the ratio was 0.90 with the $95 \%$ CI $0.68-1.19$. Mean plasma propranolol concentrations prior to the 25th, 27th and 29th (study day) doses were 29.3, 34.2 and $23.1 \mu \mathrm{g} / 1$ and are compatible with the attainment of steady state conditions of dosing. After 14.5 days the AUC for misoprostol:placebo ratio was 0.93 with the $95 \%$ CI $0.69-1.26$ and for $\mathrm{C}_{\max }$ the ratio was 0.97 with the $95 \%$ CI $0.65-1.45$. There were no statistically significant differences in $t / 2, C_{\max }$ or AUC between misoprostol and placebo and no evidence of a treatment sequence effect which could invalidate the cross-over design, either after a single dose or at steady state.

\section{Discussion}

Misoprostol has been co-administered in specifically designed drug interaction studies with aspirin, ibuprofen, piroxicam, diclofenac, naproxen and diazepam. ${ }^{6}$ In an earlier study ${ }^{2}$ we found that the AUC of propranolol increased both during and after cessation of concurrent treatment with misoprostol. Healthy volunteers took propranolol daily for 4 weeks and during the 2nd and 3rd of these weeks took misoprostol in addition. This design was selected to enable us to observe both the onset and offset of any effect of misoprostol on $\underset{2}{2}$ propranolol pharmacokinetics, although we recog- $\vec{\bullet}$ nized that it was open to interference from time $₫$ dependent influences. As our results could net rationally be explained we conducted the presen cross-over study in which the sequence of treatments was balanced to allow for any timerelated effects and the 'within subject' comparison maximized experimental precision. Our findings with the latter design indicated quite clearly that there was no significant effect of misoprostol on the pharmacokinetics of propranolol either after a single dose or at steady state.

Misoprostol does not interfere with hepatic drug metabolizing enzymes or hepatic blood flow in animals. ${ }^{7}$ We selected propranolol as a model drug as its pharmacokinetics are affected by both these factors. Our earlier work ${ }^{2}$ found that misoprostol did not alter hepatic mono-oxygenase activity as judged by antipyrine clearance; the present findings would suggest that neither does it affect liver blood flow in humans.

\section{Acknowledgements}

We thank Kathleen Cordall and Jane Ferrie for the drug assays and Sylvia Humphries for the nursing care of the volunteers. 


\section{References}

1. Akbar, A.F., Breckenridge, A.M., Hoffbrand, B.I., LennardJones, J.E. \& Wilson, D. (eds). International symposium on gastroenterology. Focus on misoprostol. Postgrad Med J 1988, 64 (Suppl 1).

2. Bennett, P.N., Fenn, G.C. \& Notarianni, L.J. Potential drug interactions with misoprostol: effects on the pharmacokinetics of antipyrine and propranolol. Postgrad Med J 1988, 64 (Suppl 1): 21-24.

3. Shah, R.R., Oates, N.S., Idle, J.R., Smith, R.L. \& Lockhart, J.F.D. Impaired oxidation of debrisoquine in patients with perhexiline neuropathy. $\mathrm{Br} \mathrm{Med} J$ 1982, 284: 295-299.

4. Danhof, M., DeGroot-van der Vis, E. \& Breimer, D.D. Assay of antipyrine and its primary metabolites in plasma, saliva and urine by HPLC and some preliminary results in man. Pharmacology 1979, 18: 210-223.

5. Gibaldi, M. \& Perrier, M. Pharmacokinetics. Dekker, New York, 1982, pp. 445-449.

6. Collins, P.W. Misoprostol: discovery, development and clinical applications. Med Res Rev 1990, 10: 149-172.

7. Schoenhard, G., Opperman, J. \& Kohn, F.E. Metabolism and pharmacokinetic studies of misoprostol. Dig Dis Sci 1985, 30 (Suppl): 126S-128S. 